\title{
قدرة الثلاميذ على حلّ التدريبات في تعليم الصرف وعلاقها بقدتهم على الإنشاء الموجّه
}

\author{
إمام هداية \\ عادة الدراسات العليا بجامعة سونان غونونج جاتي الإسلامية الحكومية باندونج \\ imam.suksesselalu@gmail.com
}

DOI: https://doi.org/10.52593/klm.01.1.06

Naskah diterima: 30-06-2020, direvisi: 02-07-2020, disetujui: 10-07-2020

\begin{abstract}
ملخص
إن الأغراض لهذا البحث هي معرفة قدرة التلاميذ على حلّ الثدريبات في تعليم الصرف في

الفصل الثامن بمدرسة الروضة الثانوية المتكملة شيلينجي باندوبج ومعرفة قدرته على الإنشاء الموجّه ومعرفة

العلاقة بنهها. والطريقة المستخدمة في هذا البحث هي الطريقة الوصفية الارتباطية. أما الأساليب لمع

البيانات فهي المقابلة والملاحظة والدراسة المكتبية والاختبار. ومن النتائج المحصولة من هذا البحث أن قدرة التلاميذ على حلّ التدريبات في تعليم الصرف تدل على القدرة كافية وهذا كما دلت عليه قيمة المتوسط على قدر عا. وحقيقة قدرتهم على الإنشاء الموجّه تدل على درجة عالية وهذا كما دلت عليه قيمة المتوسط على قدر \&N،YY. والعلاقة بنهها تدل على طبقة العلاقة متوسطة لأن حساب الارتباط على قدر Vاع, •. وكانت قدرة التلاميذعلى حلّ الثدريبات في تعليم الصرف قد أثرت في قدرتهم على الإنشاء الموجّه

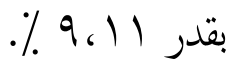
الكلمات المثتاحية: حل التدربيات، تعليم الصرف، الإنشاء الموجه
\end{abstract}

\begin{abstract}
The purpose of this study was to determine the ability of students to complete exercises in morphology learning in grade 8 Madrasah Tsanawiyah Arroudloh Cileunyi Bandung and find out their abilities in fabricated guided and find out the relationship between the two. The research method used in this study is the descriptive correlation method. The data collection techniques used are interviews, observation, literature study and tests. The results showed that the students' ability to solve exercises in morphology learning had an average grade of 64.00. And the ability of students in fabricated guided
\end{abstract}


to get an average value of 78,24 . The correlation between the two results 0,417 and the ability of students to solve exercises in morphology lessons has an influence on their ability in fabricated guided by $9,11 \%$.

Keywords: training solution, morphology learning, fabricated guided.

المقدمة

كانت اللغة العربية لا تستعمل أداة الاتصال فسبب، ولكنها تستعمل كالفة الدينية والمعرفية والتكنولوجية والفنية والثقافية. فيكون تعليم اللغة العربية ليس من اللازمات ولكنه من المفروضات. وكانت اللغة العربية للمسلمين من الأمور الضرورية لزيادة الخبرات والتعمق في الدين. ومن المعروف أن القرآن

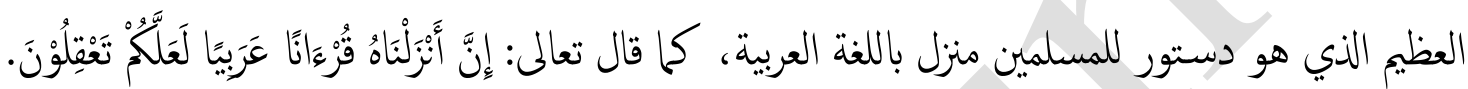
محا لا شك فيه أن اللغة العربية يحتاج إلها الفرد لتعليم العلوم الإسلامية مطلقا. واللغة العربية بجانب أن تستخدم فى القرآن الكريم كذلك تستخدم في الأحاديث النبوية والكتب التي تكون مصادر العلوم التي ألفها العلماء فى مختلف مجالات العلوم. اللغة العربية إحدى اللغات الأجنبية التي بدأ المتعلمون يتعلمونها خاصة في إندونيسيا. فاللغة العربية لللإندونسيين ليست من اللغات الأجنية الدولية فقط، وركنها لغة تتعلق بالجوانب الدينية لأن اكثثر هم من المسلمين. لذلك، كانت اللغة العربية أمرا ضروريالتعلمها وتطويرها في إندونيسيا'. من أهداف تعليم اللغة العربية عامةً تنمية قدرة المتعلم على استخدامحا شقويا كان أو كتابيا. والقدرة على استخدام اللغة في ججال التعليم تسمى بمهارات لغوية تنقسم إلى أربع حمارات وهي حمارة الاستخاع ومهارة الكلام ومهارة القراءة ومارة الكتابة. من المعروف أن حهارة الكتابة إحدى المهارات التي يستوعبها متعلم اللغة العربية. إن حهارة الكتابة عنصر حمم يستلزم أن يستوعبه متعلم اللغة بعد محارة الاستحاع والكلام والقراءة. وقيل إن حمارة الكنابة تعتبر أصعب المهارات الثلاث فى استيعابها ، حتى يصعب فيه الناطق الأصلي.

\footnotetext{
${ }^{1}$ Acep Hermawan, Metodologi Pembelajaran Bahasa Arab (Bandung: PT Remaja Rosdakarya, 2011), 6.
} 


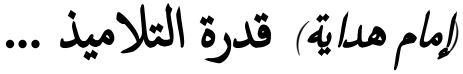

ارتباطا بذلك، إذا أراد الفرد أن يستطع الكتابة جيدا فعليه أن يستوعب عدة العناصر اللغوية

التي تشتمل على التهجئة والمفردات والقواعد اللغوية التي نشتهر بعلم النحو والصرف. إن الكنابة من المهارات اللغوية التي تحوي جانبين وها الآلي والشق العقلي. والمراد بالجانب الآلي هو قدرة على تكوين الرموز المرئية التي لم تتعلق بالمعاني المحتوية في تاك الرموز. ويتعلق ذلك بقدرة على كتابة الحروف الهجائية ومعرفة التهجئة وعلامة التزقيم في اللغات الأجنبية وما أشبه ذلك. ويشتمل الجانب العقلي على معارف كافية



من أنواع الكنابة التي توجه إلى الجانب العقلي إنشاء. وهو أحد أنواع الكتابة للتعبير عن المواقع

والمشاعر والمواقف والأفكار صريا وفعالا ليكون القارىء يفهم تلك الكتابة مناسبا لأفكار الكاتب. ومن أنواع تعليم الإنشاء إنشاء موجه وإنشاء حر. في إجراء تعليم الإنشاء الحر، يتطلب التلاميذ أن يعبروا عن أفكار حر حريا. وفي إجراء تعليم الإنشاء الموجه، يعطى التلاميذ الدوافع الممينة لكي يستطيعوا أن يعبروا عن الرسائل المنشودة في تلك الدوافع أو في تراكيب بسيطة وإما في تراكيب معقدة. إحدى المؤسسات التبوية الرسمية تحت إشراف وزارة الشؤون الدينية التي تعقد تعليم اللغة العربية هي مدرسة الروضة الثانوية المتكملة شيلينجي. اعتادا على نتاجُج الملاحظة، يعرف أن تعليم اللغة العربية إجاليا يجري جيدا. وهذا يعرف من حاسة الثلاميذ العالية ومن قيم المتحطان الجيدة بمتوسط قيهم •. . ولكن توجد المشكل في بعض الجوانب منها في جانب تعليم الإنشاء الموجه. من مظاهر تعليم اللغة العربية في مدرسة الروضة الثانوية المنكملة خاصة في تعليم الكنابة التي تقدم أسس الإنشاء الموجه يعرف أن التلاميذ لا يزالون يصعبون في تغيير الكلمات أو الممل المقيدة بالضائر وترتيب الكلمات العشوائية لتكون جملة مغيدة وإكال الجمل باختيار الكلمات المعدة.قد أوجبت مدرسة الروضة الثانوية المتكاملة في عمليهاأن يتعلم التلاميذ في المدرسة والمعهد. وهذا بمعنى أن مدرسة الروضة

2 Aziz Fakhrurrozi dan Erta Mahyudin, Metodologi Pembelajaran Bahasa Arab (Jakarta: Dirjen Pendidikan Islam Kementerian Agama, 2012), 161. 
الثانوية المتكاملة تأسست على ركايز المعهد أو تعرف باسم "مدرسة داخلية". في المعهد، يعمق التلاميذ العلوم الإسلامية وإحداها اللغة العربية وإعطائه المواد من المفردات والنحو والصرف التي تصاحها التمرينات المركزة لمساعدة قدرة التلاميذ على تعلم اللغة العربية. تعليم علم النحو والصرف من الدروس الضرورية للتلاميذ في تعلم القواعد العربية. كما قال مصطفى الغلاييني إن أهم المباحث من اللغة العربية هو النحو والصرف. لذلك، إنها من أنواع العلوم التي لا يككن فصل كل منها عن الأخر '. ولكن، اعتمادا على ملاحظة الكاتب، يعتبر التلاميذ أن تعليم الصرف أكثر جذابا وسرورا من تعليم النحو لأن في تعليم الصرف حفظ التصريف والتمرينات الصرفية المتنوعة. وهي تشتمل على تغير أنشكال الكلمات المقيدة بالضمائر والتعيين بين المذكر والمؤنث وتعيين العدد (المفرد والمثنى والجمع). ولكن التلاميذ لا يزالون يصعبون في مارسة الإنشاء الموجه. ومن المحقق أنه إذا أنشأ التلميذ إنشاء موجها بل قد أعطي المهارات في تمرينات تعليم الصرف، فهو يقدر على ممارسة الإنشاء الموجه جيدا وصحيحا. نظرا إلى المظاهر السابقة، يريد الكانب البحث عن تلك المشكلات بتحديد الموضوع قدرة التلاميذ على حلّ التدريبات في تعليم الصرف وعلاقتها بقدرتهم على الإنشاء الموجّه.

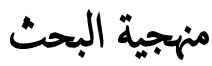

كان المدخل المستخدم في هذا البحث هو المدخل الكمي (Quantitative Entrance). يعتبر المدخل الكمي أحد المداخل المستخدمة في تنفيذ الأبحات العلمية، ويجتوي في طياته على أدوات دراسية يككن عن طريقها الوصول إلى واقع رقي له مدلوله. ويعرف بأنه أحد طرق القياس التي يتم استخداها في الأبحاث والدراسات العلمية لاختبار الفرضيات ومن ثم تطبيق النظريات والمفاهيم المكتسبة على أرض الواقع بالنسبة للأبحاث ذات الصبغة العلمية. 


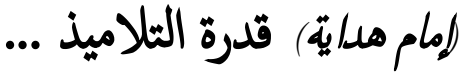

يستخدم الكاتب هذا المدخل لأن البيانات في هذا البحث تحتوي على البيانات الكمية. وهي

$$
\text { البيانات التي تأخذ شكل رقي مثل الإحصاءات والنسب المؤوية وما شابه. }
$$

طريقة البحث هي طريقة موضوعية تتبع لدراسة ظاهرة من الظواهر، بقصد تشخيصها وتحديد

أبعادها ومعرفة أسباها وطرق علاجما والوصول إلى نتائُ عامة يمكن تطبيقها، فالطريقة فن تنظيم الأفكر ، سواء للكشف عن حقيقة غير معلومة لنا، أو لاثبات حقيقة نعرفها . الطريقة التى يستخدها الكانب في هذا البحث هي طريقة الوصفية الارتباطية وهي طريقة تهدف إلى معرفة العلاقة بين المتغير والمتغير الآخر بـ أما أساليب جمع البيانات المستخدمة في هذا البحث منها أ) الملاحظة وهي أسلوب جمع البيانات الذي تأسس على الحقائق عن الوقائع المحصولة من خلال النظر المباشر. من خلال أسلوب الملاحظة، ،هدف الكلتب إلى نظر المشكلات أو المظاهر إما عن قدرة التلاميذ على حل الندريبات في تعليم الصرف وإما في قدرة التلاميذ على الإنشاء الموجه؛ ب) المقابلة، يستخدم هذا الأسلوب للحصول على البيانات التي لا يحصل عليها أسلوب الملاحظة، مثل محوع التلاميذ ومدرس مادة الصرف بمدرسة الروضة الثانوية الإسلامية المتكاملة شيلينجي والمعاملة بين المدرس والثلاميذ والمعاملة بين التلميذ والتلميذ الآخر. وموضوع المقابلة هو مدير المدرسة ومدرس مادة الصرف ومدرس اللغة العربية وبعض التلاميذ؛ ج) الاختبار ، يستخدم الاختبار أداة رئيسية لمجع البيانات عن قدرة التلاميذ على حل الندريبات في تعليم الصرف وقدرتهم على الإنشاء الموجه. ونوع الأسئة هو اختبار متعدد واختبار مقال يتكون من 10 سؤالا.

\section{العرض}

\section{أ. مفهوم حلّ التدرييات في تعليم الصرف}

ْمعرفة الأسس العلمية لكتابة رسائل الماجستير والدكتوراة، لمحمد عبد الغني ومحسن الخضيري، مكتبة الأنجلو المصرية - القاهرة ،

${ }^{6}$ Heri Gunawan, Dasar-dasar Metode Research (Bandung: Azfie Media Utama, 2011), 18. 
إذاكان التلميذيكثر التدريب والممارسة فهاراته ومعارفه أعمق. وبالعكس، سيفقد الخبرات بدون التدريب والمارسة. تعد التدريبات ضرورية لأن المتعلم الذي يريد أن يكتسب همارات يحتاج إلى تدريبات وتمرينان، ومالم تكثف الندريات لا تتحقق السيطرة على اللغة. فتعلم اللغة ليس مجرد متلق لمعلومات ومعارف فيكفيه ما يستقبل من المعلم في عرضه لدرسه أوتقديمه له، بل لابد من أن يتدرب المتعلم على ذلك لينغمس في اللغة ولثثبت في ذهنه ولتجري على لسانه وقلمه وهنا تبدوأهمية التدريبات في حمل المتعلم على ممارسة اللغة. إبل. الندريبات جمع تدريب بمعنى التمرين وهي عبارة عن التمرينات في الكناب المدرشي وأهها عملية التعلم والممارسة. يحتاج التلميذ إلى البراعة أوالمهارة في كل شيء، مثل الركض والسباحة والألعاب. إضافة إلى ذلك إن عملية التعليم والتعلم تحتاج إلى التدريبات لاستيعاب هذه المهارات ؛. أما المراد بالندريبات في هذا البحث فهوالندريبات في تعليم الصرف. وموضوعه الاسم المتمكن (أي المعرب) والفعل المتصرف. فلا يبحث عن الأسماء المبنيّة، ولا عن الأفعال الجامدة، ولا عن الحروف. (2) إن التعليم هوكل سعي منظم ومقصور لتحقيق أنشطة الثفاعل التربوي بين الشخصين وها المتعلم والمعلم اللذان يقومان بأنشطة التعليم. وموضوع الصرف في عملية التعليم والتعلم يستطيع تحقيقه جيدا إذا صاحبه التقييم من التدريبات حتى يحصل على النتائح التعليمية. والتدريب هوأحد أشكال التقييم من أنثطة عملية التعليم والتعلم حتى تظهر نتيجة التعليم'.'

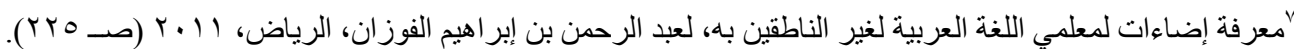

${ }^{8}$ Maghfur Wachid, Agar Berbahasa Arab Terasa Mudah (Bandung: Rosda Karya, 2008), 125.

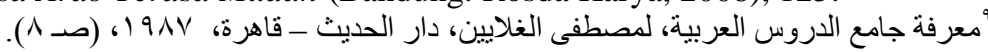

${ }^{10}$ Nana Sudjana, Dasar-Dasar Proses Belajar Mengajar (Bandung: Sinar Baru Algesindo, 2004), 28.
} 


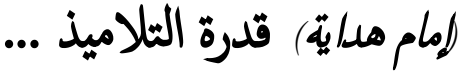

كان التدريبات تستخدم لنيل المهارات مما تعلم من قبله. وهناك مبادئ عامة في القيام بها هي: أ)

يعطى التلاميذالمعارف والخنبرات قبل أداء الندريبات؛ ب) لا تحتاج التدريبات زمنا طويلا بل تحتاج بأكثر وقت؛ ج) أن تكون التدريبات مناسبة بقدرة التلاميذ؛ د) تقدم عملية التدريبات في أمور وهة ومنفعة" .

\section{ب. بمفوم القدرة على حلّ الثدريبات في تعليم الصرف}

القدرة هي الاستطاعة للقيام بعملية شيئ. القدرة بمعنى المهارة أيضا. ويرى الكاتب أن معنى

القدرة هي قدرة الفرد على القيام بالسلوك المنظم مناسبا بالحال للوصول إلى غاية منشودة. وإن المهارة لاتنحصر على الحركة ولكنها أوسع منها، مثل ممارسة توظيف العقل المتصف بالحركة"'. وقال محد علي

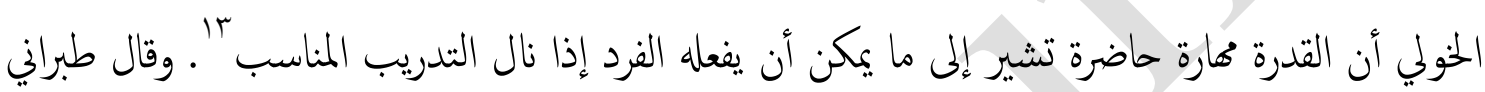
روسيان إن القدرة هي الاستطاعة والإمكانية في القيام بفعل الثيء أو بعبارة أخرى القوة المضمونة في نفس

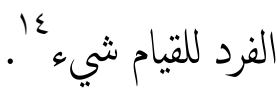

من العبارات السابقة يستنتج الكلتب أن القدرة هي سلوك الإنسان المناسب برأيه لتحقيق أغراضه المقصودة، والمهارة على استيعاب الشيئ في القيام بواجبته بجد واجتهاد. وأما المراد بالقدرة في هذالبحث فهو قدرة النلاميذ على حلّ التدريبات في تعليم الصرف.وعند سوجانا التدريب هوأحد أشكل التقييم من أنشطة عملية التعليم والتعلم حتى تظهر نتيجة التعليم ! التعليم هوكل سعي منظم ومقصور لتحقيق أنشطة التفاعل التربوي بين الشخصين وهها المتعلم والمعلم اللذان يقومان بأنشطة النعليم • قدرة التلاميذ على حلّ التدريبات في تعليم الصرف بمعنى كفاءة التلاميذ على حلّ التدريبات. هناك المزايا التدريبات وهي: أ) في وقت قصير يقدر التلاميذ على حصول المعرفة والمهارات الساعدة

\footnotetext{
${ }^{11}$ Nana Sudjana, Pengantar Evaluasi Pendidikan (Jakatra: Raja Gravindo Persada, 2008), 87.

${ }^{12}$ Muhibbin Syah, Psikologi Belajar (Jakarta : Raja Grafindo Persada, 2005), 121.

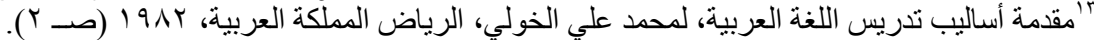

${ }^{14}$ Tabrani Rusyan, Pendekatan dalam Proses Belajar Mengajar (Bandung: Remaja Rosdakarya, 1992), 8.

${ }^{15}$ Nana Sudjana, Dasar-Dasar Proses Belajar Mengajar (Bandung: Sinar Baru Algesindo, 2004), 28.
} 
والسهلة.؛ ب) كان التلاميذ يحصلون على المهارات الساعدة والسهلة؛ ج) تنمية ممارسة التعلم مستمرة وتدريب النفس مستقلا؛ د) وفي المادة الدينية إن التلاميذ متحمسون في العمل لله" ال.

\section{ج. مؤشرات القدرة على حلّ الثدريات في تعليم الصرف}

إن المراد بمؤشرات في التعلم هي خصائص وعلامات أو استجابات يؤديها التلاميذ دلالة على هلى

أنه يملكون الكفاءة الأساسية المعينة'ال.

يستطسع التلاميذ أن يختاروا صيغا من الكلمات في القرآن الكريم أوالنصوص العربية لأن لها علاقة بمعنى الكلمة. وينفع هذا العلم لتحفيظ اللسان كي لا يخطأ في كل كلمة وأنظمة اللغة العربية في الكتابة ولفهم حقيقة ورثة اللغة العربية، أ. ههدف علم الصرف بكثه عن هذه الكلمات إلى أمورين. الأول: معرفة القواعد التي تنظم بنية هذه الكلمات، وتحدد خصائص الصيخ المستعملة لها، كما تحاول معرفة القواعد التى تربط بين بمحوعات كلمات. والثانى: استخدام هذه القواعد في تشقيق المادة اللغوية لابتكار صيغ تعبرعا يجد في حياة المجتع، وبذلك يسهم هذا العلم في تطوير اللغة للوفاء باحتياجات المجتع المتغيرة والمتطورة' ويقرر ابن جنى أن للصرف أهية كبرى، وأنه لاسبيل إلى الاستغناء عنه، لأنه يقدم لنا بموعة القواعد والضوابط التى تنظم الكلمة وتحدد بالضرورة شكالها وتؤثر في تشكيل وظيفتها. وبهتم علم الصرف

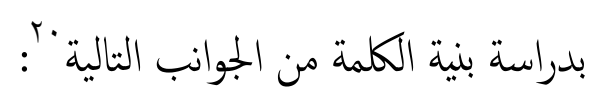
' أشتقاق صور مختلفة من جذر واحد، مثال: (ك ت ب) كتب، كاتب، كتابة، مكنوب....إخ Y. . . ما يطرأ على الكلمة من تغييرات (تقص أو زيادة)

"'معرفة الكتابة الوظيفية والإبداعية، المجالات المهارات الإنشطة والتقويم، لماهر شعبان عبد البارى، دار المسيرة للنشر والتوزيع-

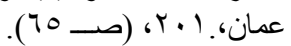

17 Aziz Fakhrurrozi dan Erta Mahyudin, Metodologi Pembelajaran Bahasa Arab, (Jakarta: Dirjen Pendidikan Islam Kementerian Agama, 2012), 29.

${ }^{18}$ Ilyas Rifa'i dan Abung Gunawan, Menguasai Ilmu Sharaf (Bandung: Fajar Media, 2014), 3.

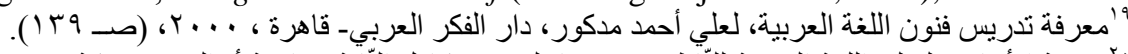

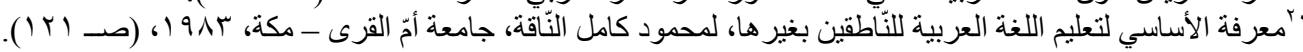




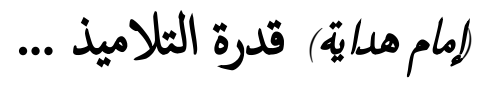

". كان الثلاميذ ماهرين حركة، مثل حفظ الكلمات، والككابة، واستحدام الأداة أوجعل شيء، وممارسة

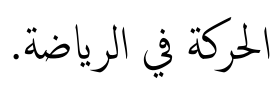

ع. تطوير مارة الثلاميذ عقلية، مثل الضرب والتقسيم والإضافة والتقليل في الحساب وتعريف عدد شيء أو شكل في دراسة الرياضية، وعلامات التقيم، وغير ذلك.

اعتادا على نتيجة الملاحظة التي قام بها الكاتب عن قدرة التلاميذ على حل عدة التدريات في تعليم الصرف بمدرسة الروضة الثانوية الإسلامية المتكاملة شيلينجي، يعرف أن المؤشرات في قدرة الثلاميذ

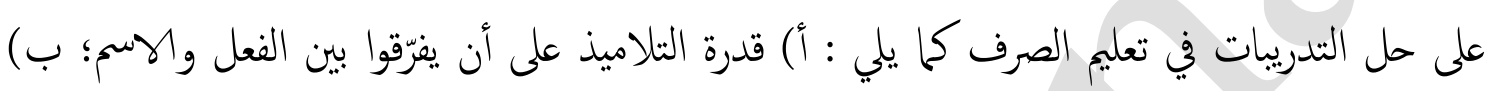
قدرة التلاميذ على أن يختاروا صياغة الكلمة المناسبة لضهائرها؛ ج) قدرة التلاميذ على أن يفرّقوا المفردات اعتمادا على نوعها (مذكر أومؤن) وعددها (مفرد، مثنى، جمع).

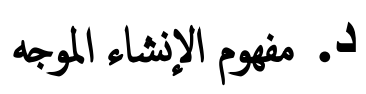

ترتيب الإنشاء الموجه تركيب وصفي يتكون من الإنشاء الموجه. وأما لفظ الإنشاء فصدر من

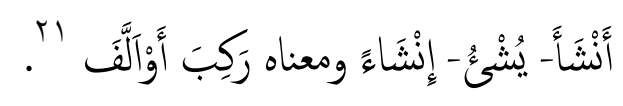

الإنشاء لفظا هوالإبانة والإفصاح عائيول في خاطر الإنسان من أفكار و ومشاعر بجيث يفهمه الآخرون. والإنشاء اصطلاحا هوالعمل المدرسي المنجبي الذي يسير وفق خطة متكاملة للوصول بالطالب

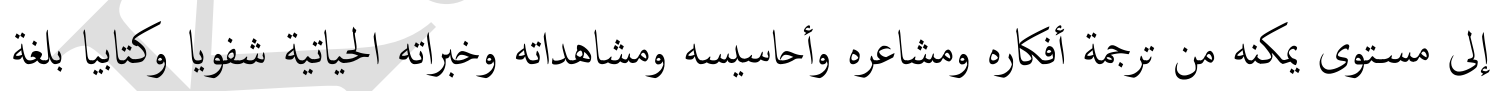

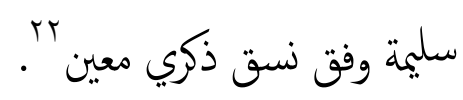

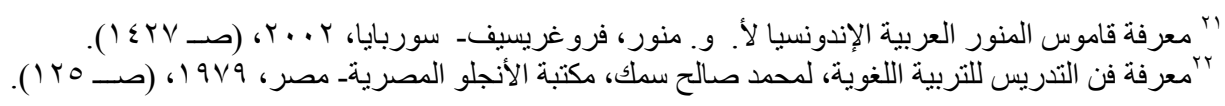


المراد بالإنشاء كل ما رجع من صناعة الكتابة إلى تأليف الكلام وترتيب المعاني من المكتبات والولايات والمساهات والإطلاقات ومناشير الاقتطاعات والأمانات والأيمان وما في معنى ذلك ككنابة الحكم

والإنشاء هوأحد وسائل النعامل بين أحد وغيره. ولذلك، الإنشاء هوتعبير الاراء أوالأفكار للإنسان من عظمة الله، لأن بالإنشاء كان تاريخ الإنسان مكتوباومفوظا. من المعروف أن التعبير ينقسم إلى قنمين ها التعبير الشفوي والتعبير الكنابي. والتعبير الكتابي هو وسيلة الاتصال بين الفرد وغيره من تفصله عنه المسافات الزمانية والمكانية، والحاجة إليه ماسة في جميع المهن. وسمي التعبير الكتابي بالإنشاء التحريري. والإنشاء التحريري ينقسم إلى قسمين هـا الإنشاء الموجه والإنشاء الحر عَب. إن الإنشاء الموجّه هوتكوين الجمل أوالفقرة البسيطة بتوجيه المدرّس وإرشاده، مثل إعطاء المثال والمملة غير الكاملة ونوها. والمراد بهاكل ما رجع من صناعة الكتابة إلى تأليف الكلام وترتيب المعاني من المكنابات والولايات والمساحمات والإطلاقات ومناشير الإقتطاعات والأمانات والأيمان وما في معنى ذلك كالكنابة الحكى ونخوها. وسمي الإنشاء الموجّه بالإنشاء المقيّد أوالكتابة المقيدة، لأن إنشاء التلاميذ محدّد بقياس يعطيه المدرّس، لذلك لا يتطلّب التلاميذ في عمليته تطوير أفكار هم حرّية. يأتي الإنشاء الموجه بعد أن يتعلم التلاميذ كنابة الحروف والنسخ والإملا. قال محمد علي الخولي وهي مرحلة تسبق الكنابة الحرة أوالإنشاء الحر. ومن الممكن أن يأخذ الإنشاء الموجّه أحد الأشكال الآتية ب؟ ا المحل الموازية

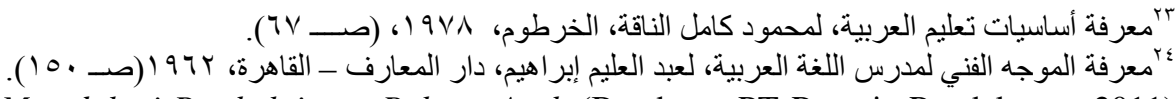

${ }^{25}$ Acep Hermawan, Metodologi Pembelajaran Bahasa Arab (Bandung: PT Remaja Rosdakarya, 2011), 124.

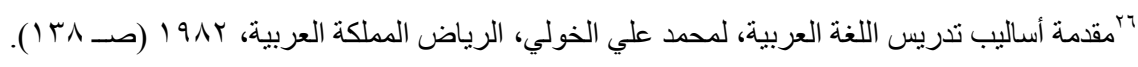




\section{(مام هداية) قدرة الثلاميذ ...}

طلب من التلميذ أن يكتب عدة جمل موازية لمجلة معينة، ويعطى الكلمات اللازمة لكنابة هذه

الجمل. مثال ذلك أن تكون الجملة النموذج: كتب الولد درسه. وتكون كلمة النعويض (البنت) على

$$
\text { ب بيل المثال. فيكتب التلميذ: كنبت البنت درسها. }
$$

تعطى للتلميذ فقرة مكتوبة ثم يطلب منه إعادة كنابة الفقرة مغيرا إحدى الكلمات الرئيسية فهها.

فإذا كانت الفقرة تدور حول شخص اسمه حاتم، يطلب منه أن يحاولها لندور حول فتاة اسمها مريم مثلا. ويستدعي هذا بالطبح تغيير الأفعال والضمائر والصفات والأحوال التي تتعلق بحاتم وجعلها تتناسب مع

$$
\text { با الهم الجديد. }
$$

طلب من التلميذ أن يملأ الفراغ في الجملة بالكملة المحذوفة التي قد تكون أداة جر أوعطف

$$
\begin{aligned}
& \text { أواستفهام أوشرط أوغير ذلك. وقد تكون الكلمة المخذوفة كلمة حتوى. } \\
& \text { ك. ت ترتيب الكلمات }
\end{aligned}
$$

تعطى للتلميذ بمحوعة من الكلمات يطلب منه أن يرتبها ليعمل منها جملة صحيحة. مثال ذلك:

$$
\text { هلمة، آكل، تفاحة، عاصم. تصبح هذه: أكل عاصم تفاحة حلوة. }
$$

تعطى للتلميذ بموعة غير مرتبة من الجمل، ويطلب منه أن يرتبها ليعمل منها فقرة منكاملة.

فالتلميذ هنا لا ينتج كلمات أوتراكيب.كل ما عليه أن يفهم الجمل المعطاة له ويفهم العلاقات التي بينها،

$$
\text { 7. ب يقوم بترتبها زمنيا أومكانيا أومنطقيا أوبأية طريقة أخرى مناسبة. }
$$


تعطى للتلميذ جملة يطلب منه أن يحولها إلى منفية أومثبتة أواستفهامية أوخبرية أوتعجبية، أوإلى الماضي أوالمضارع أوالأمر ، أوإلى المبني للمعلوم أوالمبني للمجهول، أوإلى غير ذلك من التحويلات. ( n

تعطى للتلميذ بملتان يطلب منه أن يصلها معا ليكون منها جملة واحدة باستخدام أداة تحدّد

$$
\text { 1. أبكال أوتترك له حرية تحديدها. }
$$

يعطى للتميذ جزء من الجملة ويطلب منه إكمالها بزيادة جملة رئيسية أوغير رئيسية. مثال

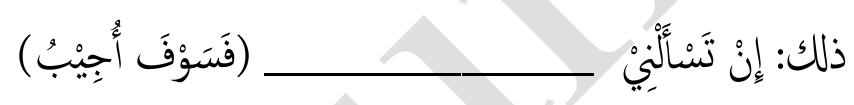

والإنشاء يجتاج إلى القدرة على ربط الكلمات والجمل حتى تكون متكملة. فلذلك كان الإنشاء من معارة اللغة الصعبة إذا كان مقارنة بالمهارات اللغوية الأخرى. وهذا لأن في هذه العملية، يجب على الكاتب أن يقدر على النعبير عن الأراء باستخدام قواعد اللغة الصحيحة. وأما الغرض من الإنشاء فهوتدريب التلاميذ على استخدام المفردات العربية ومعرفة تركيب الجملة والقواعد المتعقة به. طابقا بالرأي السابق، هناك عدة أساليب تدريب الإننشاء الموجّه على تدريس اللغة العربية عند

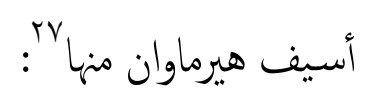

ا ـ التبديل، مثل تحويل أحد العناصر في الجملة وتحويل الجملة من فعل المعلوم إلى الجملة من فعل الجهول أوعكسها والجملة الإيجابية إلى الجملة السلبية أوعكسها والجملة الخبرية إلى الجملة الاستفهامية

$$
\text { مثلوعكسها والمجلة التي تتزكب من فعل مضارع إلى فعل ماضي أوعكسها ونهوها. }
$$
فَاطِمَةُ

\footnotetext{
${ }^{27}$ Acep Hermawan, Metodologi Pembelajaran Bahasa Arab (Bandung: PT Remaja Rosdakarya, 2011), 164.
} 
(مام هداية) قدرة الثلاميذ ...

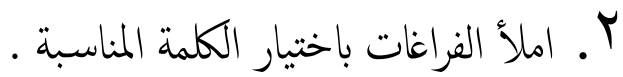

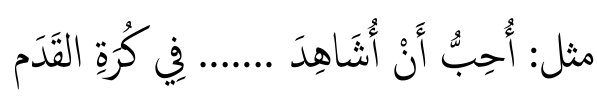

ب. ترتيب الكلمات لتكون جملة مفيدة.

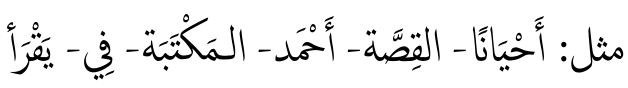

ع. ـ ترتيب الجمل لتكون فقرة مفيدة.

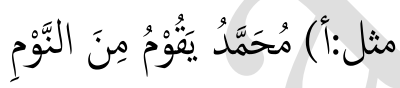

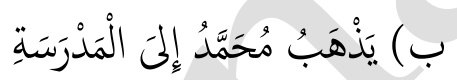

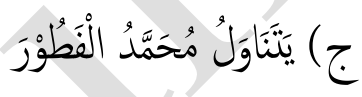

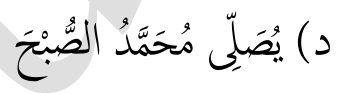

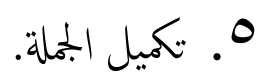

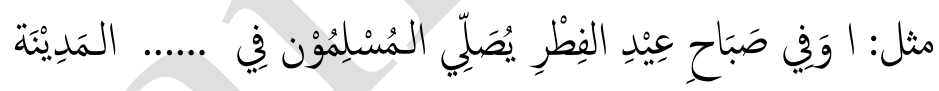

7. - إبابة الأسئلة عن القراءة

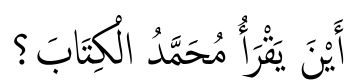

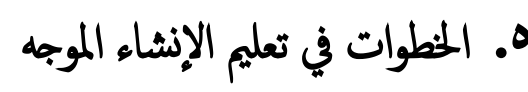

التعليم هوالعملية التربوية الخطوطة قبلها وتتجه إلى الغرض والتخطيط لتسير الدراسة. وعند عبد العليم إبرهيم هوعملية يراد بها إحداث تغير في سلوك الكلاءن الحي. وهذا السلوك الذي يراد تغييره بالتعليم

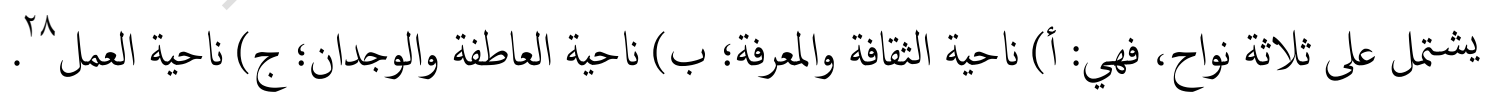

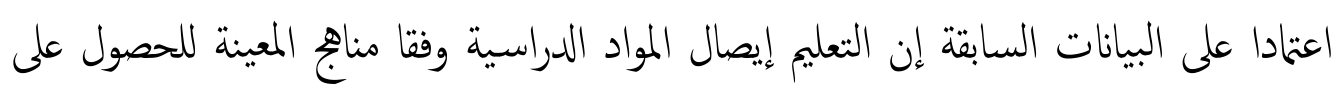
الأغراض المطلوبة، وهي التغيير في السلوك إما من ناحية الثقافة والمعرفة أوناحية العاطفة والوجدان

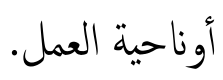

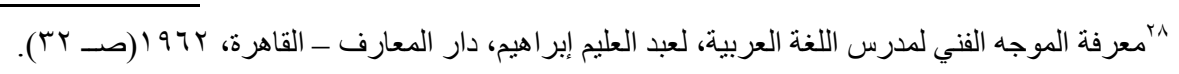


أما المراد بالنعليم في هذا البحث فهوالنعليم في تعليم الإنشاء الموجه.من المعروف أن تعليم الإنشاء الموجه مرحلة من مراحل التعليم قبل الإنشاء الحر. وقال محمد على الخولي إنه يسمى أيضا بالإنشاء المقيد". وإن الإنشاء الموجه يدرب عليه النلاميذ بطرق كثيرة كما يلي: أ) مله فراغ النص؛ ب) كتابة الموضوع مع الاستعانة بالإجابة عن الأسئلة؛ ج) كنابة بطاقة تهنئة وفقا لنموذج؛ د) كنابة قصة مع الاستعانة بالعناصر أوالأسئلة؛ هـ) إكمال الناقص في المحادثة؛ و كتابة الرسالة وفقا لنموذج ·. يقسم خطوات في تعليم الإنشاء الموجه إلى حلقين، والحلقة الأولى تتبع الطرق الآتية: () استعال كلمات في جمل تامة، ويحسن اختبار هذه الكلمات مما يعرف النلاميذ؛ ؟) ثكملة جملة ناقصة بوضع كلمة يختارها التلاميذ من كلمات أمامهم، أوياتوتا بها من عندهم؛ ب) الإجابة عن أسئلة عامة متنوعة، أوعن أسئلة في موضوع قرأه التلاميذ؛ ع) ترتيب قصة تعرض أجزاؤها على التناميذ غير مرتبة؛ 0) التعبير عن الصور؛ 7) كتابة العبارة بعد تغيير بعض كلمات بكلمات تقابلها لاستقامة المعنى؛ V) كنابة بعض الجمل عن عمل يقوم به التلاميذ، أوعن شئ يشاهده؛ N) تلخيص قصة قصيرة قرأها التلاميذ أوسمعوها؛ 9) تكوين

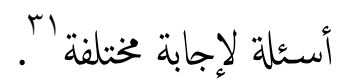

\section{و. واقعية قدرة الثلاميذعلى حلّ الثدريات في تعليم الصرف}

لمعرفة واقعية قدرة الثلاميذعلى حلّ التدريبات في تعليم الصرف في مدرسة الروضة الثانوية المنكملة في شيلينجي كولون باندونج تحليل جميع أجوبة النلاميذ عن عشرة أسئلة الاختبار من خمسة وعشرين تلميذا بمثابة العينة في هذا البحث.

واعتمد تنظيم أسئلة الاختبار على أربع مؤشرات وهي القدرة على التفريق بين الفعل والاسم صحيحا والقدرة على اختيار صيغ الكلمة المناسبة لضمائرها والقدرة على تفريق المفردات اعتمادا على نوعها وعددها والقدرة على تطبيق المفردات في الجمل البسيطة. 


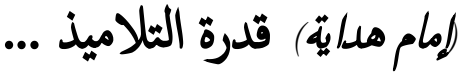

وبعد التيام بالاختبار وتحليله وجد الكاتب النتائُ الآتية: ( ) يعرف أن المجموع من الاختبار

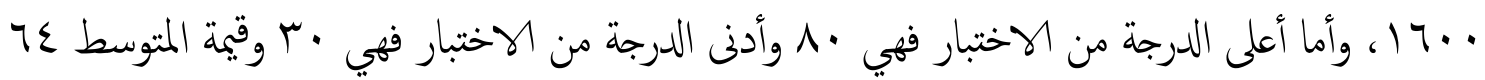
تدل على درجة منخفضة للأها تقع بين ل0 - 09 في معيار التفسير؛ r) ومن البيان السابق وجد

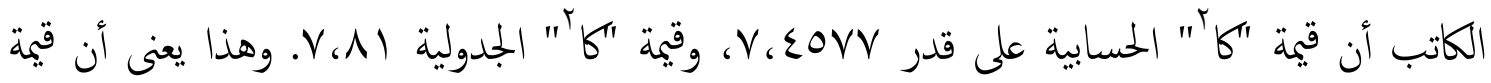

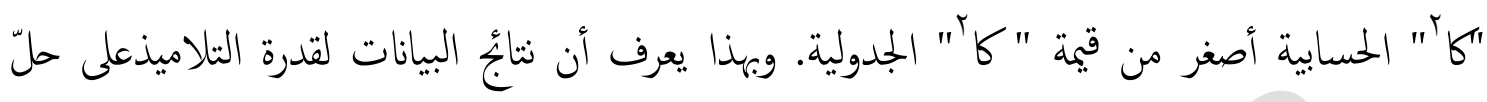
التدرييات في تعليم الصرف لها توزيح متعدل. ز. - ماقعية قدرة الثلاميذ على الإنشاء الموجّه

لمعرفة قدرة التلاميذ على الإنشاء الموجّه في مدرسة الروضة الثانوية المتكاملة في شيلينجي كولون باندونج يتأسس الكاتب على مجميع أجوبة التلاميذ عن عشرة أسئلة مقدمة إلى خمسة عشرين تلميذا بمثابة العينة في هذا البحث. واعمد تنظيم أسئة الاختبار على خمس مؤشرات وهي القدرة على إكلال الكلمات المخذوفة باستتخدام الكلمات المعدة و القدرة على ككمة المجل المفرغة باستخدام الكلمات المناسبة و القدرة على تريب الكلمات غير المرتبة لتكون جملة مفيدة و القدرة على تغيير الجملة مناسبا إلى نوع وعدد فاعلها و القدرة على استخدام الكلمات في جملة مفيدة. وبعدما قام الكاتب بالاختيار لمعرفة قدرة الثلاميذ على الإنشاء الموجّه فيحصل على النتأُ الآتية: يعرف أن أعلى درجة النتيجة من الوختبار هي .. أوأدنى درجة النتيجة من الاختبار هي لV

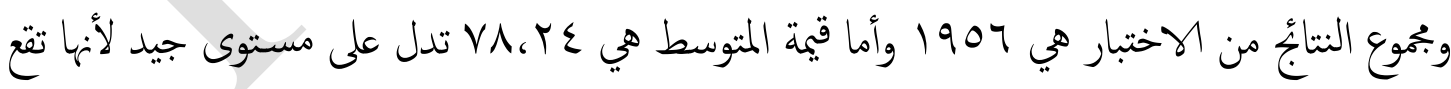

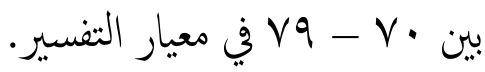

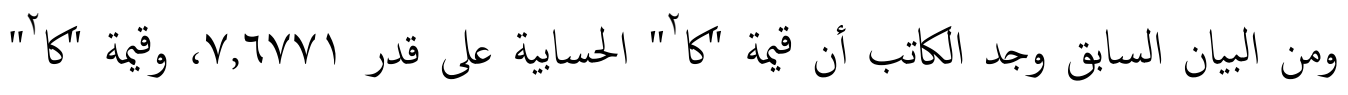

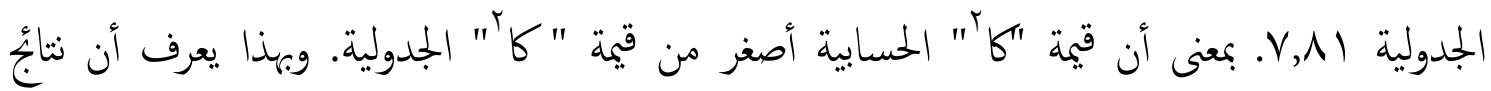
التيانات لقدرة التلاميذ على الإنشاء الموجّه لها توزيع جيد. 


\section{ح. واقعية العلاقة بين قدرة الثلاميذعلى حلّ الثدريات في تعليم الصرف و قدرتم على الإنشاء الموجّه}

لمعرفة حقيقة العلاقة بين قدرة التلاميذعلى حلّ الندريات في تعليم الصرف وقدرتهم على الإنثاء

الموجّه، فيبحث عهها الكانب بالخطوات الآتية: أ) تعيين استواء الانحدار المستقيم؛ ب) تعيين درجة الحرية للخطأ ؛ ج) تعيين درجة الحرية لعدم الموافقة ؛ د) تعيين المتوسط لتربيع الخطأ؛ هـ) تعيين المتوسط لتربيع عدم الموافقة؛ و) تعيين "ف" عدم الموافقة؛ ز) تعيين قيمة " ف " في الجدول على مستوى الدلالة ه٪ ومن الحساب السابق يعرف أن قيمة "ف" الحسابية = Y,Yl و "ف" الجدولية 9, 9. فاستنبط الكاتب أن الانحدار بين قدرة التلاميذعلى حلّ التدريبات في تعليم الصرف وقدرتهم على الإنشاء الموجّه مستقيم لأن قيمة "ف" الحسابية أصغر من "ف" الجدولية.

كما هو المعروف أن توزيع البيانات في المتغير السيني والمتغير الصادي متعادل و والنحدار

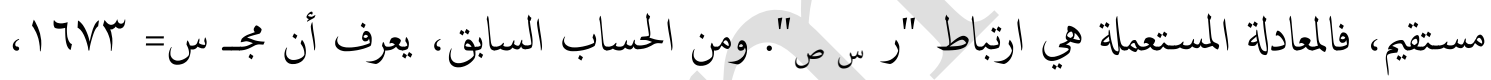

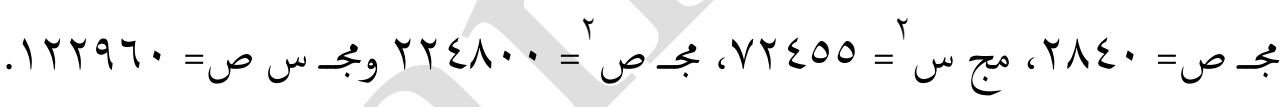
من الحساب المذكور يعرف الكاتب أن قيمة معامل الارتباط Vاع, • فارتباطه إيجابي. هذه القيمة تدل على مستوى متوسط لأن قيمة وع, • تقع بين اع, •- •7, · في معيار التقييم. وبعد ذلك يعتمد حساب قيمة "ت" في القائمة باستعال مستوى الدلالة ه٪ ودرجة الحرية (دب)

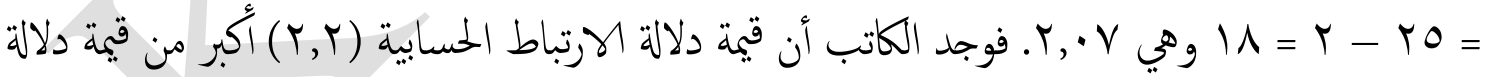
الارتباط الجدولية (Y,V) فتدل هذه النتيجة على أن الفرضية المقترحة (أ) مقبولة وكانت الفرضية الصفرية مردودة بمعنى أن بين المتغيرين (قدرة التلاميذعلى حلّ التدريبات في تعليم الصرف وقدرتهم على (Ho)

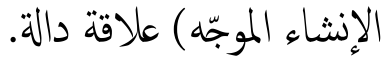


على أساس نتيجة الحساب يعرف الكاتب أن قدرة التلاميذعلى حلّ التدريبات في تعليم الصرف

تؤثر في قدرته على الإنشاء الموجّه على قدر 11,9 ٪ وهناك عوامل أخرى على قدر 91, •9 ٪ داخلية كانت أم خارجية تؤثر في قدرتهم على الإنشاء الموجّه.

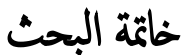

بعد القيام بالبحث في مدرسة الروضة الثانوية المتكملة شيلينجي باندونج وتحليل بياناته يقدم

الكانب النتائج الآتية: ( ) إن قدرة التلاميذعلى حلّ التدريبات في تعليم الصرف تدل على قدر عاب بمعنى أن هذه القدرة كافية لأن القيمة المصولة تقع بين •7 - 79 في معيارالتفسير. ؟) إن حقيقة قدرته على

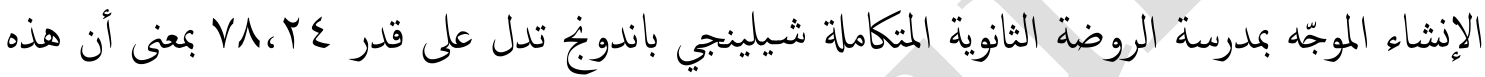
القدرة تدل على درجة عالية لأن التمة المحصولة تقع بين •V - V V في معيارالتفسير. r) إن العلاقة بينها تدل على حساب الارتباط على قدر لاع, · بمعنى أن طبقة العلاقة متوسطة لأها تقع بين اع,.••T, · فى معيار النفسير. وكانت قدرة التلاميذعلى حلّ التدريبات في تعليم الصرف قد أثرت في قدرته على الإنشاء الموجّه بقدر 11, 1 ٪. بالمعنى أن هناك عوامل أخرى تؤثر فيها مثل البيئة، والمنهج والطريقة وغيرها من العوامل الأخرى داخلية كانت أو خارجية على قدر 91،, •9 ٪.

\section{المصادر والمراجع}

Agar Berbahasa Arab Terasa Mudah, Maghfur Wachid, Bandung Rosda Karya, 2008. Al Asa>si> li Ta'li>m al Lughah al Arabiyyah li al Na>thiqi>na Bighairiha>, Mahmud Kamil Al Naqah, Mekkah Ja>miah Ummul Qura>, 1983. Al Asa $>$ si $>y a>t$ Ta'li $>$ m al Arabiyyah, Mahmud Kamil Al Naqah, Khurtum, 1978. Al Kita>bah al Wadzi>fiyyah wa al Ibda>iyyah, Mahar Sa'ban Abd Al-Bari, Oman Da>r al Masi>rah, 2001.

Al Muwajjih Al Fanniy Li Mudarrisii Al Lughah Al 'Arabiyyah, Abdul Alim Ibrahim, Kairo Da>r al Ma'a>rif, 1968. 
Asālīb Tadrīs al-Lughah al-Arabiyyah, Muhammad Ali Al-Khuli, Riyadh al-Mamlakah al-Arabiyyah, 1982.

Dasar-dasar Metode Research, Heri Gunawan, Bandung Azfie Media Utama, 2011.

Dasar-Dasar Proses Belajar Mengajar, Sudjana, Bandung Sinar Baru Algesindo, 2004.

Fan al Tadri>s li> al Tarbiyyah al Lughawiyyah, Muhamad Shalih Samki, Mesir Maktabah Al Anjalu>, 1979.

Idhaāt Li Mu'allimī Al Lughah Al 'Arabiyyah Li Ghairi Al Nāthiqīna Bihā, Al Abdurrahaman Ibrahim Fauzan, Riyadh Al Mamlakah Al Arabiyyah As Su'udiyyah, 2011.

Ja>mi al-Duru>s al-Arabiyyah. Musthafa Al-Ghalayain, Qairo Da>r Hadi>ts, 1987.

Kamus al Munawir, A. W. Munawir, Surabaya Progresif, 2002.

Menguasai Ilmu Sharaf, Ilyas Rifa'i dan Abung Gunawan, Bandung Fajar Media, 2014.

Metode Penelitian Kuantitatif Kualitatif Dan R\&D, Sugiyono, Bandung Alfabeta, 2016.

Metodologi Pembelajaran Bahasa Arab, Acep Hermawan, Bandung PT Remaja Rosdakarya, 2011.

Metodologi Pembelajaran Bahasa Arab, Aziz Fakhrurrozi dan Erta Mahyudin, Jakarta Dirjen Pendidikan Islam Kementerian Agama, 2012.

Pendekatan dalam Proses Belajar Mengajar, Tabrani Rusyan, Bandung Remaja Rosdakarya, 1992.

Pengantar Evaluasi Pendidikan, Nana Sudjana, Jakatra Raja Gravindo Persada, 2008.

Psikologi Belajar, Muhibbin Syah, Jakarta Raja Grafindo Persada, 2005.

Tadri >s Funu>n al Lughah al Arabiyyah, Ali Ahmad Madkur, Qairo Da>r al Fikri al Arabi>, 2000. 